\title{
p53 is essential for DNA methylation homeostasis in naïve embryonic stem cells, and its loss promotes clonal heterogeneity
}

\author{
Ayala Tovy, ${ }^{1,5}$ Adam Spiro, ${ }^{2,5}$ Ryan McCarthy, ${ }^{3}$ Zohar Shipony ${ }^{2}$ Yael Aylon, ${ }^{1}$ Kendra Allton, ${ }^{3}$ \\ Elena Ainbinder, ${ }^{4}$ Noa Furth, ${ }^{1}$ Amos Tanay, ${ }^{2}$ Michelle Barton, ${ }^{3}$ and Moshe Oren ${ }^{1}$ \\ ${ }^{1}$ Department of Molecular Cell Biology, ${ }^{2}$ Department of Computer Science and Applied Mathematics, The Weizmann Institute \\ of Science, Rehovot 76100, Israel; ${ }^{3} \mathrm{MD}$ Anderson Department of Epigenetics and Molecular Carcinogenesis, The University \\ of Texas MD Anderson Cancer Center, Houston, Texas 77030, USA; ${ }^{4}$ Department of Life Sciences Core Facilities, The Weizmann \\ Institute of Science, Rehovot 76100, Israel
}

DNA methylation is a key regulator of embryonic stem cell (ESC) biology, dynamically changing between naïve, primed, and differentiated states. The $\mathrm{p} 53$ tumor suppressor is a pivotal guardian of genomic stability, but its contributions to epigenetic regulation and stem cell biology are less explored. We report that, in naïve mouse ESCs (mESCs), p53 restricts the expression of the de novo DNA methyltransferases Dnmt3a and Dnmt3b while upregulating Tet1 and Tet2, which promote DNA demethylation. The DNA methylation imbalance in p53-deficient $\left(\mathrm{p}^{5} 3^{-I}\right)$ mESCs is the result of augmented overall DNA methylation as well as increased methylation landscape heterogeneity. In differentiating $\mathrm{p}^{5} 3^{-/-} \mathrm{mESCs}$, elevated methylation persists, albeit more mildly. Importantly, concomitant with DNA methylation heterogeneity, $\mathrm{p}^{-/-}$mESCs display increased cellular heterogeneity both in the "naïve" state and upon induced differentiation. This impact of p53 loss on 5-methylcytosine (5mC) heterogeneity was also evident in human ESCs and mouse embryos in vivo. Hence, p53 helps maintain DNA methylation homeostasis and clonal homogeneity, a function that may contribute to its tumor suppressor activity.

[Keywords: DNA methylation; p53; stem cells]

Supplemental material is available for this article.

Received March 22, 2017; revised version accepted May 22, 2017.

DNA methylation is a key epigenetic mark that is correlated with the major transitions during embryogenesis and other developmental processes. Differentiation and dedifferentiation of mouse embryonic stem cells (mESCs) provide a model for analyzing the regulation and possible functional roles of DNA methylation in maintaining pluripotency and facilitating differentiation. For example, when $\mathrm{mESC}$ s are induced to undergo differentiation, the transcriptional network ensuring pluripotency is silenced, and de novo DNA methylation is observed at promoters of key pluripotency factors (Thiagarajan et al. 2014). Conversely, when serum-maintained mESCs are moved to serum-free conditions with two kinase inhibitors (2i), their developmental potential is enhanced alongside substantial loss of DNA methylation (Leitch et al. 2013). These transitions recapitulate early embryonic stages (Nichols and Smith 2009; Martin Gonzalez et al. 2016), but the mechanisms modulating DNA methylation remain to be fully characterized. The DNA methyla-

\footnotetext{
${ }^{5}$ These authors contributed equally to this work.

Corresponding author: moshe.oren@weizmann.ac.il

Article published online ahead of print. Article and publication date are online at http://www.genesdev.org/cgi/doi/10.1101/gad.299198.117.
}

tion machinery is crucial for lineage specification, and mice lacking functional DNA methyltransferases (DNMTs) fail to develop properly (Siegfried and Cedar 1997; Smith and Meissner 2013); therefore, more comprehensive elucidation of the regulation of DNA methylation is pivotal to understanding the pluripotent state.

In mammals, DNA methylation is governed by three DNMTs: Dnmt3a and Dnmt3b, responsible for setting de novo DNA methylation patterns, and Dnmt1, required primarily for maintenance of such patterns. In addition, TET enzymes (Tet 1 and Tet 2 in mESCs) facilitate demethylation by catalyzing oxidation of 5-methylcytosine $(5 \mathrm{mC})$ to 5 -hydroxymethylcytosine $(5 \mathrm{hmC})$, which, by sequential oxidation steps, provides the substrate for reversal to unmethylated cytosine (Ficz et al. 2011). Recent studies show that DNA methylation patterns in ESCs are likely determined by a balance between methylation and demethylation rather than copied from a pre-established

(C) 2017 Tovy et al. This article is distributed exclusively by Cold Spring Harbor Laboratory Press for the first six months after the full-issue publication date (see http://genesdev.cshlp.org/site/misc/terms.xhtml). After six months, it is available under a Creative Commons License (Attribution-NonCommercial 4.0 International), as described at http://creativecommons.org/licenses/by-nc/4.0/. 
template (Shipony et al. 2014). Accordingly, the regulation of DNMT and TET genes may ultimately determine the dynamics of DNA methylation in pluripotent states. p53 is a pivotal tumor suppressor, playing major roles in maintaining genome stability (Levine and Oren 2009; Qiu et al. 2011; Carvajal and Manfredi 2013; Aylon et al. 2016). Functional p53 is linked to maintenance of the epigenome (Levine and Greenbaum 2012) and specifically DNA methylation of retroelements (Leonova et al. 2013). Moreover, p53 depletion facilitates reprogramming of differentiated cells into ESC-like induced pluripotent stem cells (iPSCs), further implicating p53 in epigenetic robustness (Shin et al. 2013; Shetzer et al. 2014). Epigenetic stress, such as global DNA methylation loss, can trigger p53-induced cell death (Jackson-Grusby et al. 2001; Chiappinelli et al. 2016). Although p53 knockout mice are viable, they display frequent developmental defects (Molchadsky et al. 2010) along with early onset cancer (Donehower et al. 1992; Rivlin et al. 2015). At a young age, prior to cancer formation, p53 knockout mice display deregulation of the DNA methylation machinery (Park et al. 2005). Abnormal DNA methylation patterning is frequently observed in cancer (Schnekenburger et al. 2014) and may be associated with intratumoral heterogeneity (Landau et al. 2014; Pisanic et al. 2017). This raises the interesting question of whether functional deregulation of p53, as occurs in a majority of cancers, impinges on normal DNA methylation patterning and thereby promotes epigenetic promiscuity.

To further elucidate whether p53 is important for epigenetic robustness and naïve-state cellular homogeneity, we studied the impact of p53 deficiency on the DNA methylation landscape and its maintenance in mESCs. We report that, in naïve mESCs, p53 regulates the expression of genes encoding key components of the DNA methylation machinery, including Dnmt3a, Dnmt3b, Tet1, and Tet2. Moreover, Tet1 and Tet2 are direct p53 transcriptional targets. Consequently, p53 loss promotes imbalance between $5 \mathrm{mC}$ and $5 \mathrm{hmC}$, leading to increased methylation in naïve mESCs and augmenting the heterogeneity of their methylation landscape. Notably, p53 loss impacts $5 \mathrm{mC}$ heterogeneity also in vivo in mouse embryos as well as human ESCs (hESCs). Hence, p53-dependent regulation of $5 \mathrm{mC}$ integrity is conserved through evolution. DNA hypermethylation is maintained, albeit more mildly, when $\mathrm{p} 53^{-/-}$mESCs are induced to differentiate. Importantly, the aberrant methylation patterns in p53deficient mESCs are associated with increased phenotypic population heterogeneity in both naïve and differentiating conditions as well as a failure to properly regulate genes associated with either pluripotency or differentiation.

Together, these observations imply that p53 regulates DNA methylation homeostasis and contributes to the maintenance of both the naïve state of ESCs and their ability to respond properly to differentiation signals. Hence, lack of proper p53 activity, commonly associated with loss of genome stability, may shift the normal balance between methylation and demethylation and contribute to epigenome instability as well.

\section{Results}

\section{p53 modulates the expression of Dnmt and Tet genes} in $\mathrm{mESCs}$

To determine whether p53 impacts regulation of DNA methylation in mESCs, several independent mESC clones were generated from either wild-type or p53 knockout $\left(\mathrm{p} 53^{-/-}\right)$mice (Materials and Methods) and maintained in naïve ground-state conditions $(2 \mathrm{i}+\mathrm{LIF})$. One prominent feature of the ground state is global DNA hypomethylation as a result of high activity of TET enzymes (Hackett et al. 2013) and/or restricted activity of DNMTs. Remarkably, elevated expression of Dnmt3a and Dnmt3b RNA (Fig. 1A, NT) and protein (Supplemental Fig. S1A, NT) relative to wild-type mESCs was observed in the ground state in $\mathrm{p} 53^{-/-}$mESCs. Upon induced differentiation (4d treatment with retinoic acid [RA]), Dnmt3b expression dropped markedly in wild-type mESCs, yet both Dnmt3a and Dnmt3b mRNA remained elevated in the $\mathrm{p} 53^{-/-}$ mESCs (Fig. 1A, RA). These observations suggest that p53 either directly or indirectly restricts the expression of de novo DNMTs in both "naïve" and differentiating mESCs. Notably, published p53 ChIP-seq /chromatin immunoprecipitation [ChIP] combined with highthroughput sequencing) data (Li et al. 2012) indicate the presence of p53-binding sites (p53BSs) in proximity to the transcription start sites (TSSs) of all Dnmt genes, in genomic regions decorated by the enhancer marks H3K4me1 and H3K27ac (Supplemental Fig. S1C). Indeed, we could confirm p53 binding to these regions both in the ground state and following RA treatment (Fig. 1B).

Tet1 and Tet2, but not Tet3, are highly expressed in mESCs (Ficz et al. 2011). Remarkably, ground-state levels of Tet1 and Tet2 mRNA were significantly reduced in p53 ${ }^{-/-}$mESCs (Fig. 1C, NT), implicating p53 as a putative positive regulator of both Tet genes in "naïve" mESCs. In contrast, while Tet1 and Tet2 expression decreased robustly in RA-treated wild-type mESCs, this decrease was partly (Tet1) or entirely (Tet2) compromised in $\mathrm{p} 53^{-/-}$ cells, which now expressed more Tet 1 and Tet2 mRNA than their wild-type counterparts (Fig. 1C, RA; Supplemental Fig. S1B). To further corroborate these findings, we performed a comparative analysis of the commonly studied mESC line J1 and three independent clones derived from J1 cells by CRISPR/Cas9-mediated p53 knockout $\left(\mathrm{J} 1 \mathrm{p} 53^{-/-}\right)$; confirmation of knockout is shown in Supplemental Figure S1, D (Western) and E (FACS). Notably, compared with their parental J1 cells, the p53-clones displayed elevated Dnmt3a and Dnmt3b RNA in both naïve and RA-treated conditions (Supplemental Fig. S1F), consistent with the pattern observed in mESCs derived from wild-type and $\mathrm{p} 53^{-/-}$mice. Likewise, the behavior of Tet 1 and Tet 2 in the CRISPR-generated clones also closely resembled that of the mESCs derived from p53 ${ }^{-/-}$mice (Supplemental Fig. S1G). In sum, p53 restricts the expression of Dnmt $3 a, b$ in both naïve and RA-treated mESCs while regulating Tet 1 and Tet2 positively in naïve mESCs but becomes a negative regulator of Tet 1 and Tet2 upon RA treatment. 


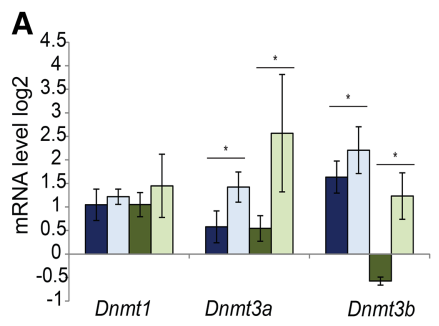

C

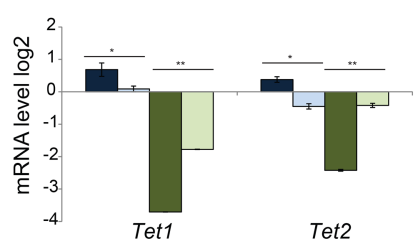

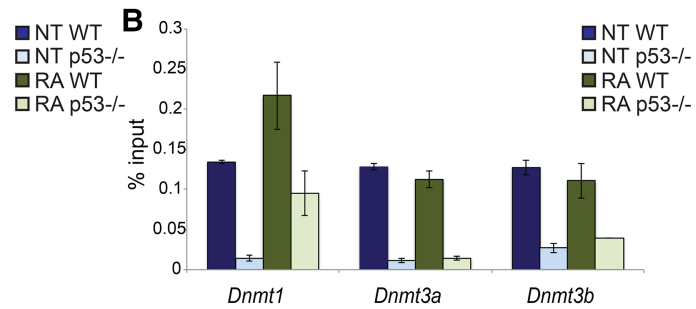

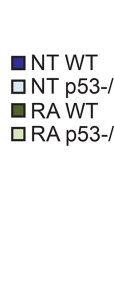

$$
\text { D } \quad 0.4
$$

0.4
0.35

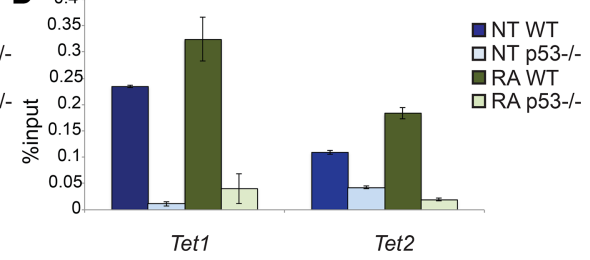

Figure 1. p53 regulates the DNA methylation machinery in mESCs. (A) mESC clones derived from either wild-type (WT) or $\mathrm{p}^{-1} 3^{-1}$ - mice (three and four independent clones, respectively) were cultured in $2 \mathrm{i}+\mathrm{LIF}$ (nontreated [NT]) or treated for $4 \mathrm{~d}$ with $1 \mathrm{mM}$ RA. RNA was subjected to quantitative RT-PCR (qRT-PCR) analysis of the indicated genes. Values were normalized to $\beta$ actin mRNA and averaged for each genotype. Error bars indicate $\mathrm{SE}$ from three biological repeats. $(*) \quad P$-value $<0.05$. $(B)$ Cells treated as in $A$ were subjected to ChIP with anti-p53 polyclonal antibody (CM5) or anti-Flag antibody as a negative control. Precipitated DNA was subjected to qPCR analysis with primers corresponding to reported p53BSs located in proximity to the TSSs of Dnmt1, Dnmt3a, and

$D n m t 3 b$ (Supplemental Fig. S1C). p53 ChIP values are expressed as percentage of input DNA. (C) RNA prepared as in $A$ was subjected to qRT-PCR analysis of Tet1 and Tet2. $\left(^{*}\right) P$-value $<0.05$; $\left(^{* *}\right) P$-value $<0.01$. (D) ChIP analysis was performed exactly as in $B$ but with qPCR primers corresponding to reported p53BSs located upstream of the Tet1 and Tet2 genes (Supplemental Fig. S1C).

ChIP-seq data (Li et al. 2012) indicated that p53 binds upstream of the TSS of Tet1 and also weakly upstream of the TSS of Tet2 (Supplemental Fig. S1C) in mESCs; moreover, the upstream p53BS of Tet1 coincides with a major H3K27ac peak in a region also decorated with H3K4me1, suggestive of a putative p53-regulated enhancer. Indeed, ChIP analysis confirmed p53 binding to the upstream regions of both genes in mESCs, albeit weaker in Tet2 (Fig. 1D). To test whether these regions can confer p53-dependent transcriptional regulation, they were cloned into a luciferase reporter plasmid harboring a minimal promoter. As shown in Supplemental Figure S1H, both regions displayed enhancer activity in wild-type mESCs, which was attenuated in p53 $3^{-/}$mESCs. Together, the above results suggested that loss of p53 function might lead to perturbation of the normal methylation/ demethylation balance in mESCs.

\section{p53 is needed to maintain DNA hypomethylation} in the ground state

Decreased expression of Tets and increased expression of Dnmts are expected to drive aberrant DNA hypermethylation in naïve $\mathrm{p} 53^{-/-} \mathrm{mESCs}$. We therefore used reduced representation bisulfite sequencing (RRBS) to compare DNA methylation in wild-type and $\mathrm{p} 53^{-/-}$mESCs. For all informative CpGs (as defined in the Materials and Methods), we calculated the difference in the average percentage of methylation between three $\mathrm{p} 53^{-/-}$clones combined together and three wild-type clones combined together. As seen in Figure 2A, p53 $3^{-/}$mESCs exhibited elevated ground-state methylation relative to wild-type mESCs (Fig. 2A, quadrants $\mathrm{i}$ and ii; Supplemental Fig. S2A). RA induced a substantial increase in global DNA methylation in both wild-type and $\mathrm{p} 53^{-/-}$mESCs (Supplemental Fig. S2B,C, respectively). Although methylation remained mostly higher in RA-treated $\mathrm{p} 53^{-/-}$ESCs than in wild-type mESCs (Fig. 2A, quadrants ii and iv;
Supplemental Fig. S2D), a substantial number of CpGs that were hypermethylated in naive $\mathrm{p} 53^{-/-}$mESCs became hypomethylated relative to wild-type mESCs (Fig. 2A, quadrant i). Supplemental Table 1 lists genes associated with stem cell maintenance or differentiation that are hypermethylated in $\mathrm{p} 53^{-/}$ESCs relative to wild-type mESCs in either naïve-state (nontreated) or RA-treated cells.

Of note, cumulative DNA methylation profiling of all informative $\mathrm{CpGs}$ indicated that while all naïve wildtype $\mathrm{mESC}$ clones appeared to behave quite uniformly, the $\mathrm{p}^{-1-}$ clones displayed greater interclonal heterogeneity (NT in Supplemental Fig. S2E,F, respectively). Thus, although all p53 knockout clones displayed elevated methylation at the naive state, the extent of hypermethylation varied among clones (Fig. 2B, top panel). A similar differential trend, albeit less heterogeneous, was observed also upon RA treatment (Fig. 2B, bottom panel). In sum, proper maintenance of DNA methylation in mESCs in the ground state as well as upon induced differentiation is perturbed in the absence of p53.

\section{Hydroxymethylation is deregulated in $p 53^{-/-}$mESCs}

In hESCs, DNA methylation stability is maintained primarily through dynamic repetitive cycles of methylation-demethylation rather than replication-dependent "persistent" memory (Shipony et al. 2014). Hydroxymethylation $(5 \mathrm{hmC})$ promotes demethylation by oxidation of the methyl group of $5 \mathrm{mC}$. The fact that naïve p53 mESCs underexpress TETs (Fig. 1C) while up-regulating Dnmt3a and Dnmt3b (Fig. 1A) suggested that the observed increase in their DNA methylation might be due to an imbalance between methylation and demethylation. Standard DNA methylation analysis by bisulfite conversion does not distinguish between $5 \mathrm{mC}$ and $5 \mathrm{hmC}$ (Huang et al. 2010). Therefore, the DNA samples used for the RRBS analysis in Figure 2A were next subjected 
A
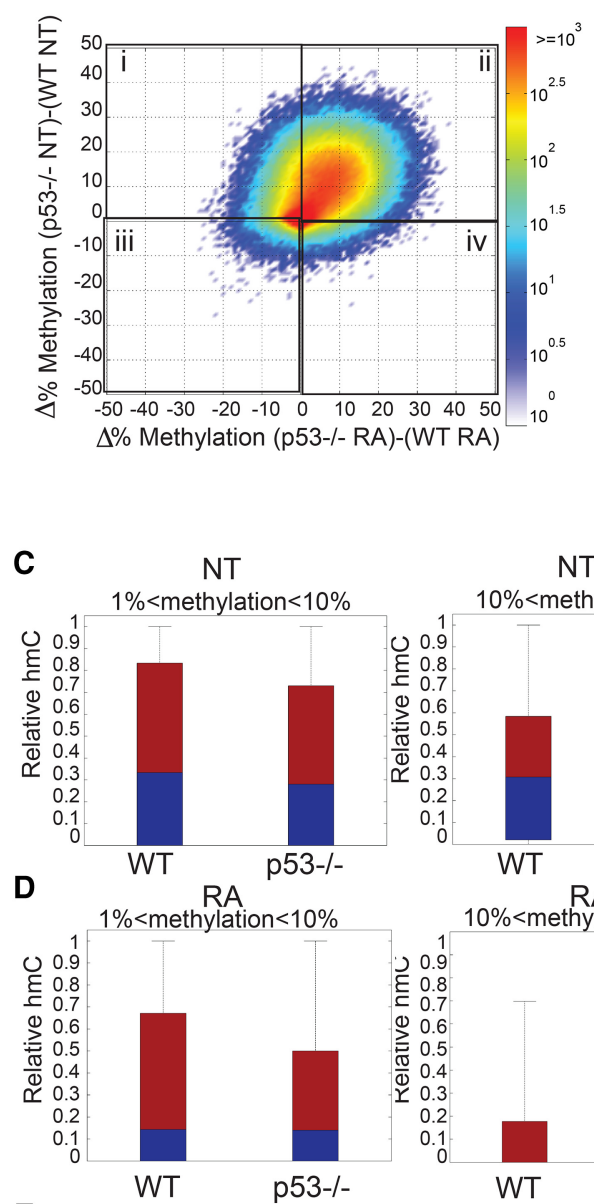

E

E

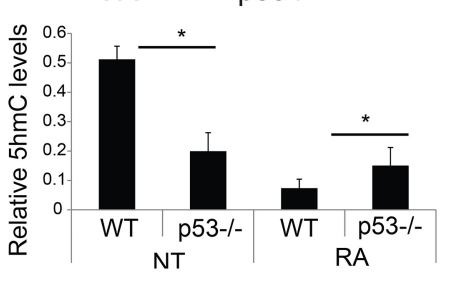

to oxidative RRBS (OX-RRBS) (Booth et al. 2012), which captures only $5 \mathrm{mC}$ (scheme in Supplemental Fig. S2G). In agreement with the global methylation data in Figure 2A, the OX-RRBS analysis (Supplemental Fig. S2H) also showed that CpGs with a high average percentage of $5 \mathrm{mC}$ were more abundant in the p53 ${ }^{-/-}$mESCs than in the wild-type mESCs both in the ground state and upon RA treatment. This supports the notion that the global DNA methylation $(5 \mathrm{mC}+5 \mathrm{hmC})$ differences between p53 $3^{-/}$and wild-type mESCs are largely due to $5 \mathrm{mC}$.

Next, to compare relative $5 \mathrm{hmC}$ levels, DNA regions covered in sufficient depth in both the RRBS and OXRRBS libraries were binned into three groups according to the increase in their percentage of methylation in p53 $3^{-/-}$mESCs relative to wild-type mESCs. On the assumption that the difference between the RRBS value and the OX-RRBS value represents $5 \mathrm{hmC}$, we then calculated for each group the average fraction of $5 \mathrm{hmC}$ out of its total methylation $(5 \mathrm{mC}+5 \mathrm{hmC}$, deduced from RRBS). In-
Figure 2. p53 regulates the DNA methylation-hydroxymethylation balance in ground-state and RA-treated mESCs. $(A)$ Heat map representation of the DNA methylation differences between $\mathrm{p} 53^{-1-}$ and wild-type (WT) mESCs in the ground state (nontreated $[\mathrm{NT}] ; Y$-axis) and in response to RA ( $X$-axis). Each dot represents a single $\mathrm{CpG}$ with the indicated differences in percentage of methylation between the listed cell types and conditions. (B) Quantification of the mean change in DNA methylation in four independent $\mathrm{p} 53^{-/-}$mESC clones relative to wild-type mESCs in the ground state (top panel) and upon RA treatment (bottom panel). For each CpG, the methylation value averaged for all three wild-type clones was subtracted from the methylation value of the same CpG in each individual $\mathrm{p} 53^{-/-}$ clone. Red and blue represent the second and third quartiles, respectively. $(C)$ Estimated relative proportion of $5 \mathrm{hmC}$ out of total DNA methylation in the ground state for highly covered RRBS and oxidative RRBS (OX-RRBS) reads. Reads were binned according to the difference in their percentage methylation between $\mathrm{p} 53^{-/-}$(average of four clones) and wild-type (average of three clones) mESCs. Values were obtained by subtracting OX-RRBS values from RRBS values for the same reads. Corresponding relative $5 \mathrm{hmC}$ levels are shown as fraction of total methylation. $(D)$ Estimated relative proportion of $5 \mathrm{hmC}$ out of total DNA methylation following RA treatment, calculated for highly covered RRBS and OX-RRBS reads as in $C$. (E) DNA from wild-type and $\mathrm{p} 53^{-/-}$ mESCs without and with RA treatment was subjected to ELISA with a $5 \mathrm{hmC}$-specific antibody. Results are averaged from four p53-/- clones and three wild-type clones. deed, the impact of $5 \mathrm{hmC}$ was attenuated in naïve $\mathrm{p} 53^{-1-}$ mESCs, particularly in relatively highly methylated regions (Fig. 2C, middle and right panels), supporting the hypothesis that compromised hydroxymethylation contributes to the accumulation of excessive $5 \mathrm{mC}$ in the DNA of these cells. Upon RA treatment, in agreement with the prominent decrease in Tet expression (Fig. 1C), the contribution of $5 \mathrm{hmC}$ to total methylation was markedly attenuated (Fig. 2D).

The above global observations were next validated for a number of representative DNA regions by hMeDIP (hydroxymethylated DNA immunoprecipitation), which directly assesses DNA hydroxymethylation (Supplemental Fig. S2I). Finally, comparative analysis of DNA from three wild-type and three $\mathrm{p}^{-1-}$ clones using a $5 \mathrm{hmC}$-specific antibody in an ELISA confirmed that $\mathrm{p} 53^{-/-} \mathrm{mESCs}$ possess markedly reduced $5 \mathrm{hmC}$ levels in the naïve state while failing to down-regulate their $5 \mathrm{hmC}$ effectively in response to RA (Fig. 2E). Thus, p53 maintains DNA 
methylation homeostasis in mESCs by regulating the expression of Dnmts and Tets in both naïve and differentiating states.

\section{DNA methylation patterns differ between wild-type and $p 53^{-/-}$mESCs}

Restricted DNA methylation serves to maintain ESCs in an undifferentiated state. Interestingly, previous studies showed that elevated DNA methylation correlates with cellular heterogeneity (Singer et al. 2014). We therefore asked whether individual cells within the wild-type and p53 $3^{-/-}$ESC populations differ in their extent of DNA methylation. To that end we labeled the cells with a $5 \mathrm{mC}$ antibody followed by flow cytometry analysis; this method successfully detected the reduced methylation in Dnmt3a and Dnmt3b double-knockout mESCs and Dnmt1, Dnmt3a, and Dnmt3b triple-knockout mESCs (Supplemental Fig. S3A). In agreement with our observations for mESCs from p53 knockout mice (Fig. 2A), the three $\mathrm{p} 53^{-/-}$clones derived from $\mathrm{J1}$ cells by genome editing also displayed a substantial increase in overall $5 \mathrm{mC}$ content relative to control J1-derived wild-type clones (Fig. 3A). Importantly, in all p53-deleted clones, the distri- bution of $5 \mathrm{mC}$ levels among individual cells within the population was significantly greater than in their wildtype controls, as indicated by standard deviation analysis (Robust coefficient of variation) (Fig. 3B). This suggests that loss of p53 in mESCs promotes greater cell-to-cell heterogeneity in overall DNA methylation. Moreover, p53 $3^{-/-}$mouse embryos displayed significantly elevated $5 \mathrm{mC}$ cell-to-cell heterogeneity relative to wild-type embryos (Fig. 3C), confirming that our observation also applies in vivo.

To further investigate the relationship between $\mathrm{p} 53$ and DNA methylation heterogeneity, we turned again to the DNA methylation sequencing data analyzed in Figure 2. Specifically, we quantified the levels and patterns of DNA methylation of individual sequencing reads from the RRBS libraries, comparing wild-type and $\mathrm{p} 53^{-/-}$ mESCs. RRBS DNA segments were defined as fully unmethylated, fully methylated, low methylated $(>50 \%)$, or high methylated $(>50 \%)$. Reads were then clustered according to their pattern of distribution between these methylation level bins and their behavior in wild-type mESCs relative to $\mathrm{p} 53^{-/-} \mathrm{mESCs}$; the results are shown in Figure 3D. As expected, in the naïve state, many DNA regions were completely unmethylated in both
A
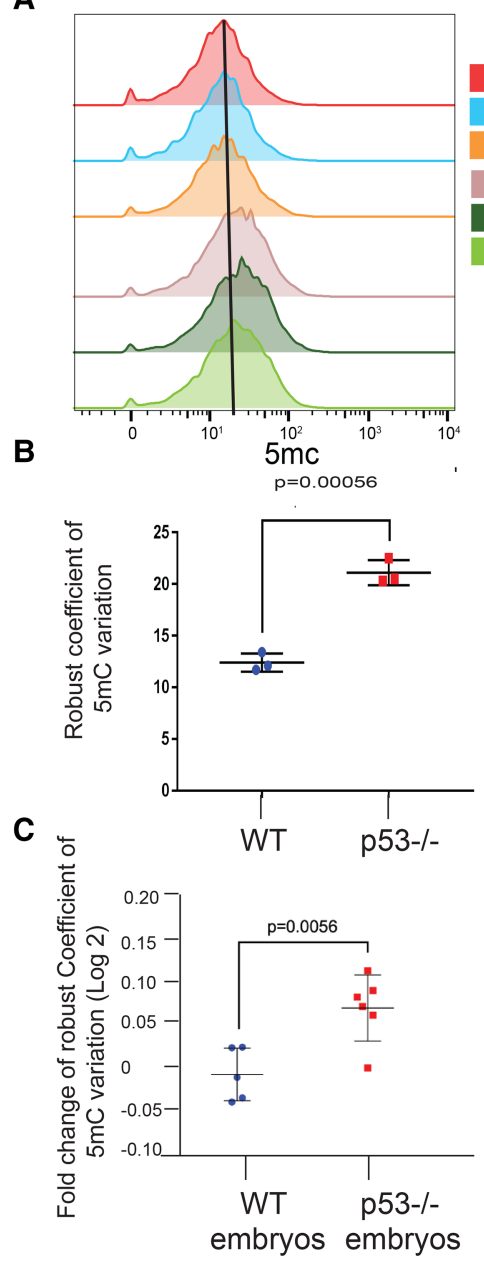

\section{D}

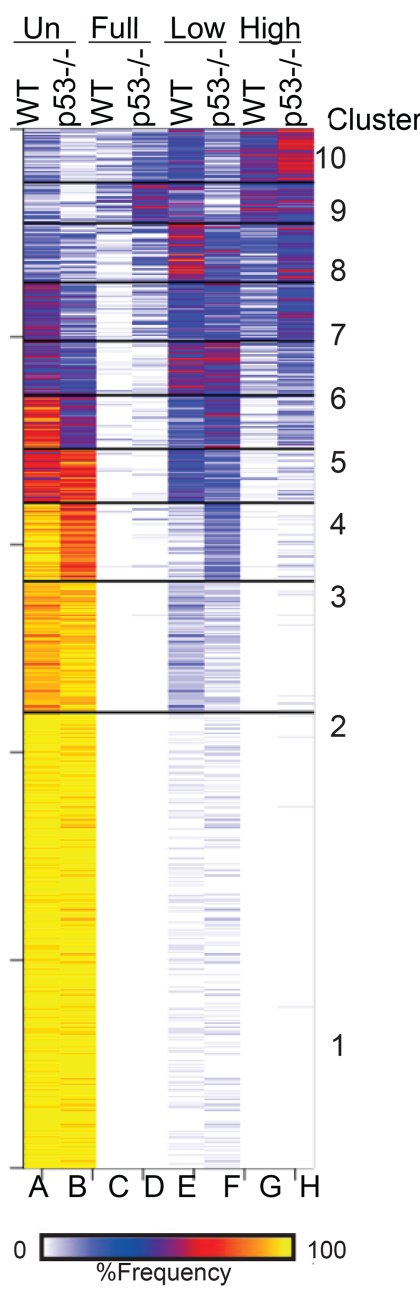

Figure 3. p53 loss increases DNA methylation heterogeneity. (A) Histogram overlays of the distribution of $5 \mathrm{mC}$ levels in three $\mathrm{J} 1 \mathrm{mESC}$ control clones (WT-J1) and three p53 knockout clones derived from J1 cells by CRISPR/Cas9 gene editing. $5 \mathrm{mC}$ levels were determined by staining with antibody against $5 \mathrm{mC}$ followed by FACS analysis. (B) Relative distribution of $5 \mathrm{mC}$ values in the three individual clones of each genotype as represented by robust coefficient of variation, calculated from the data in $A$. Robust coefficient of variation was calculated using the FloJo software. (C) Wild-type (WT) and $\mathrm{p}^{-/-}$embryonic day 11.5 (E11.5) embryos (littermates from two crosses between $\mathrm{p} 3^{+/-}$heterozygous mice) were dissociated into single cells. Cell suspensions were stained with antibody against $5 \mathrm{mC}$ and analyzed by FACS as in $A$. Each circle/square indicates an individual embryo. The robust coefficient fold change after normalizing $5 \mathrm{mC}$ intensity to the mean of the wild-type embryos in each litter is plotted. $(D)$ Clustering analysis of DNA segments covered by at least 20 reads, clustered by average methylation levels in ground-state mESCs. Columns represent no methylation (un), 100\% methylation (full), partially methylated below 50\% (low), and partially methylated above $50 \%$ (high). Each row represents a distinct RRBS DNA segment. 
genotypes (Fig. 3D, cluster 1, columns A and B). Importantly, individual DNA segments displaying a relatively uniform prevalent methylation pattern in wild-type mESCs (e.g., completely unmethylated) (Fig. 3D, cluster 3 ) acquired a more heterogeneous pattern upon loss of p53, reflected by a broader distribution between methylation level bins (see also Fig. 3D, clusters 5, 7, and 8). Furthermore, some of the regions displaying increased heterogeneity in $\mathrm{p} 53^{-/-}$cells tended to overlap with regions that normally become extensively methylated upon exposure of wild-type mESCs to RA (e.g., Fig. 3D, clusters 7,8; Supplemental Fig. S3B). Together, our observations imply that lack of $\mathrm{p} 53$ permits the propagation of heterogeneous excessive DNA methylation in naïve mESCs.

The absence of p53 interferes with the ability of mESCs to maintain the naïve state and undergo proper differentiation

To investigate whether the elevated epigenetic heterogeneity in $\mathrm{p} 53^{-/-}$mESCs affects their transcriptional landscape, we performed RNA sequencing (RNA-seq) analysis on two representative wild-type clones and all four p53 knockout mouse-derived mESC clones in the ground state and following $4 \mathrm{~d}$ of RA treatment. Approximately 600 genes were significantly differentially expressed (fold difference $>2 ; q$-value $<0.05$ ) between wildtype and $\mathrm{p} 53^{-/-}$mESCs in the ground state (nontreated), and this increased to $\sim 1700$ genes upon RA treatment. Genes expressed more abundantly in naïve wild-type mESCs (Supplemental Table 2) were enriched for apoptosis and cell proliferation (Supplemental Fig. S4A), processes impacted by p53. However, this group was also enriched for genes involved in negative regulation of cell differentiation, supporting the notion that p53 plays a role in maintaining ESCs in the naïve state. In agreement, genes expressed more abundantly in $\mathrm{p} 53^{-/-}$nontreated mESCs (Supplemental Table 2) were enriched for genes positively associated with cell differentiation, suggesting a failure to keep those genes tightly repressed in the naïve state. Following RA treatment, differentiating wild-type mESCs became enriched for pathways such as glutathione metabolism and hedgehog signaling (Supplemental Table 3; Supplemental Fig. S4B, cluster 14), which are important for proper ESC differentiation (Maye et al. 2004; Yanes et al. 2010). Analysis of all significant differentially expressed genes identified numerous clusters with distinct expression patterns (Supplemental Fig. S4B). Gene set enrichment analysis (GSEA) indicated that naïve wild-type mESCs are enriched for a "stemness" gene expression profile (Fig. 4A, left). Interestingly, a similar group of genes was enriched in $\mathrm{p} 53^{-/-}$mESCs upon RA treatment (Fig. 4A, right), while such genes are normally repressed by RA in wild-type mESCs. Validation of a subset of those genes by quantitative RT-PCR (qRT-PCR) is shown in Supplemental Figure S4C. Conversely, Prdm14, previously reported to repress the DNA methylation machinery (Grabole et al. 2013), was down-regulated in $\mathrm{p} 53^{-/-}$ mESCs relative to wild-type mESCs (Supplemental Fig.
S4D); this might contribute to the increased expression of Dnmt genes in p53-null mESCs.

We speculated that the aberrant gene expression pattern observed in $\mathrm{p} 53^{-/-}$mESCs might result from the existence of a heterogeneous population in which some of the cells fail to maintain a precise pluripotency transcriptional program in the ground state and fail to completely shut off this program upon differentiation cues. Thus, we performed single-cell mass flow cytometry analysis (CyTOF) and compared the levels of 16 protein markers (PMs) in J1 cells and two p53-deleted derivatives thereof in the naïve state and following RA treatment. The data were visualized with the aid of spanning tree progression analysis of density normalized events (SPADE) (Qiu et al. 2011), which extracts cellular hierarchy by comparing the ratio of PMs in each wild-type and p53 $3^{-/-}$cell. As seen in Figure $4 \mathrm{~B}$, distinct nodes are more strongly represented in each of the genotypes in the naïve state (left panel) and following RA treatment (right panel, the color representation indicates the relative intensity of staining with each of the pertinent antibodies in the wild type vs. p53 ${ }^{-/-}$clones).

This analysis indicates that wild-type and $\mathrm{p} 53^{-/-}$ mESCs harbor different heterogeneous populations. Examples of some of the PMs responsible for this heterogeneity are presented in Figure 4C. Of note, PAX6, OTX2, and Brachyury - transcription factors that contribute to ESC differentiation (Tsankov et al. 2015) —are visibly expressed in a portion of nontreated naïve $\mathrm{p} 53^{-/-}$mESCs. On the other hand, following a differentiation cue, a bigger portion of $\mathrm{p} 53^{-/-} \mathrm{mESCs}$ still retains expression of the pluripotency marker OCT4 while failing to up-regulate the differentiation factor FOXA2 in a manner similar to the wild-type cells. Essentially similar results were obtained with mESC clones derived from wild-type and $\mathrm{p} 53^{-/-}$ mice both nontreated (Supplemental Fig. S5) and RAtreated (Supplemental Fig. S6). Together, these singlecell analysis results confirm that the absence of p53 indeed promotes cellular heterogeneity in both the naïve and RA-treated states, affecting the regulation of pluripotency and differentiation-associated proteins.

\section{The absence of p53 increases mESC intraclonal heterogeneity}

Population heterogeneity is markedly reduced in the naive state, associated with an overall largely hypomethylated genome (Singer et al. 2014). Our results thus far suggested that for these processes to properly take place, mESCs rely in part on p53. We therefore examined the phenotypic manifestations of p53 deficiency.

Colonies of wild-type and $\mathrm{p} 53^{-/-} \mathrm{mESCs}$ in the ground state were morphologically indistinguishable. However, a clear difference emerged when we monitored alkaline phosphatase (AP) activity, a biomarker of undifferentiated stem cells and an indicator of cellular "stemness" (Rho et al. 2006). Ground-state wild-type colonies displayed relatively little colony-to-colony variability in AP staining intensity (Fig. 5A [top], B [NT]). In contrast, although the median AP staining intensity was similar between the genotypes, $\mathrm{p} 53^{-/-}$mESCs displayed a broader intercolony 


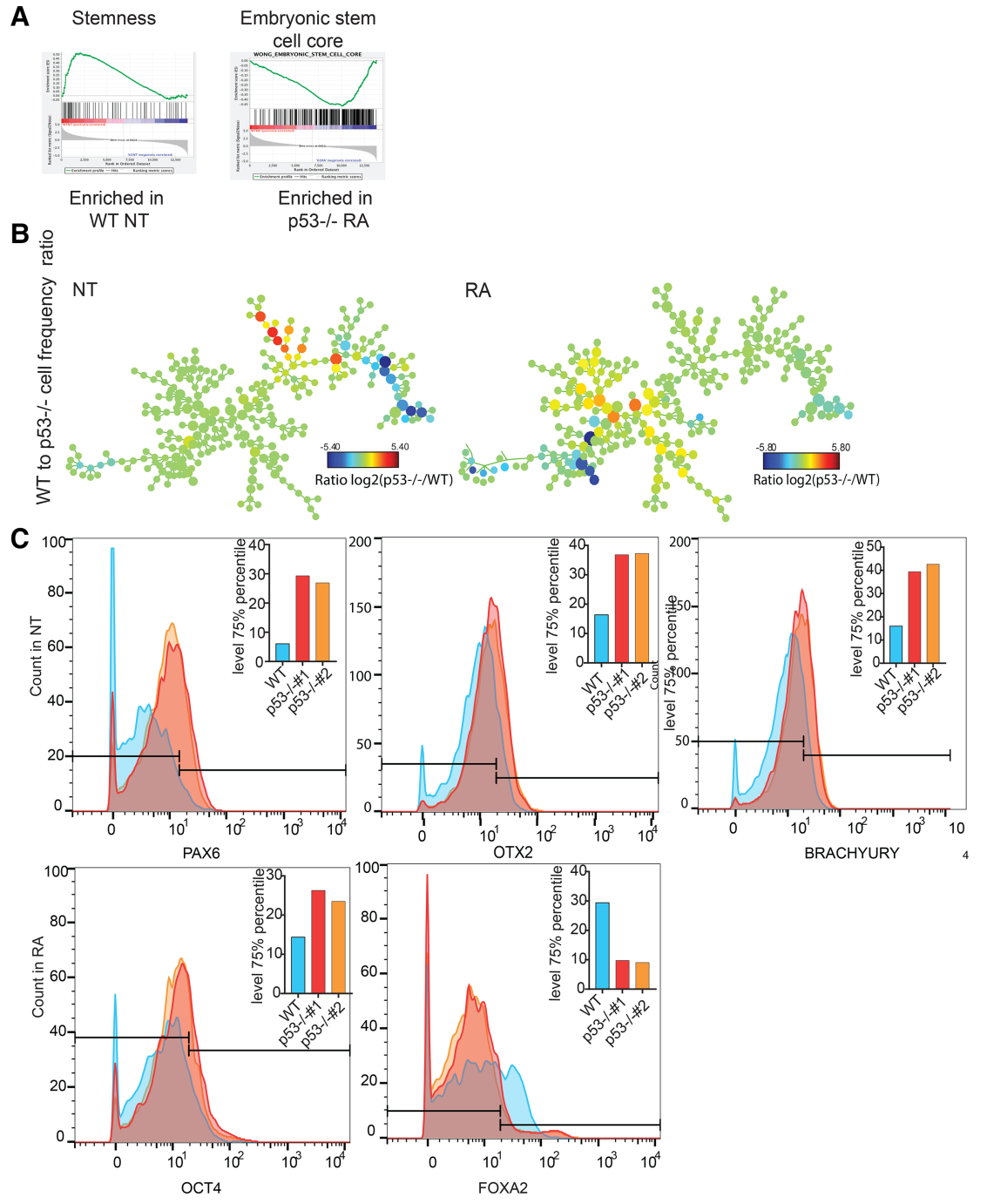

Figure 4. p53 loss promotes mESC population heterogeneity. (A) GSEA of RNA-seq data from two wild-type (WT) and three p53 $3^{-/-}$mESC clones nontreated (NT) or exposed to RA. While nontreated wild-type mESCs showed enrichment for data set RAMALHO_STEMNESS_UP (false discovery rate $[\mathrm{FDR}]<0.01), \mathrm{p} 53^{-/-} \mathrm{mESC}$ showed enrichment for a similar data set (WONG_EMBRYONIC_STEM_CELL_CORE; FDR $<0.01$ ) following RA treatment. $(B)$ Spanning tree progression analysis of density normalized events (SPADE) of combined nontreated and RA-treated wild-type and $\mathrm{p} 53^{-/-}$mESCs following integration of 16 protein markers from CyTOF analysis. The color scheme in SPADE nodes represents relative enrichment for the $\mathrm{p} 53^{-/-}$to wild-type subpopulation ratio. (C) Histogram overlays of the indicated transcription factors as deduced from the SPADE analysis of a control J1 clone (WT) and J1-derived clones depleted of p53 by CRISPR-Cas9 genome editing. The bar plot depicts the level of the $75 \%$ percentile in the indicated clone. distribution (Fig. 5B, NT). Thus, the absence of p53 renders the ESC population more phenotypically heterogeneous. Induction of differentiation reduces AP activity (Palmqvist et al. 2005), as was readily apparent in wildtype mESCs (Fig. 5A, RAd2). Notably, also under those conditions, the distribution of AP intensities remained broader in the p53 ${ }^{-/-}$mESCs (Fig. 5A [bottom], B [RA]). Hence, consistent with the gene expression analysis, these observations suggest that, under naïve conditions, a portion of $\mathrm{p} 53^{-/-}$mESCs may exist in an aberrant state characterized by reduced "stemness," while, in response to differentiation cues, some of the $\mathrm{p} 53^{-/-}$mESCs may fail to turn off the pluripotency program effectively.

To explore this possibility more closely, we immunostained wild-type and $\mathrm{p} 53^{-/-}$mESCs for the pluripotency protein OCT4 and the ectoderm protein FGF5 (Radzisheuskaya et al. 2013). Remarkably, while nontreated wild-type mESCs hardly stained for FGF5, a significant portion of $\mathrm{p} 53^{-/-}$mESCs stained visibly (Fig. 5C); staining was heterogeneous within individual colonies, with only some of the cells being positive. Thus, in ground-state conditions, p53-deficient mESCs fail to maintain homo- geneity, and some cells within the colony seem to spontaneously undergo differentiation. Likewise, whereas all wild-type mESCs turned off OCT4 expression efficiently upon RA treatment, some $\mathrm{p} 53^{-1-}$ colonies retained substantial OCT4 expression (Fig. 5C). Specifically, while for both FGF5 and OCT4 the median staining intensity was comparable in RA-treated wild-type and $\mathrm{p} 53^{-/-}$ mESCs, the p53-deficient cultures displayed much greater colony-to-colony and cell-to-cell variability (Fig. 5C,D). Together, these observations suggest that only a subset of $\mathrm{p} 53^{-/-}$mESCs responds properly to differentiation cues.

\section{p53 depletion increases the extent and heterogeneity of DNA methylation in hESCs}

To determine whether the effects of p53 on the overall extent and cell-to-cell heterogeneity of DNA methylation are conserved in human cells, we used shRNA to stably deplete p53 expression in hESCs. These sh-p53 cells as well as their p53-proficient controls were then subjected to $5 \mathrm{mC}$ analysis by flow cytometry, essentially as done for mESCs in Figure 3A. As shown in Figure 6A, p53 
A

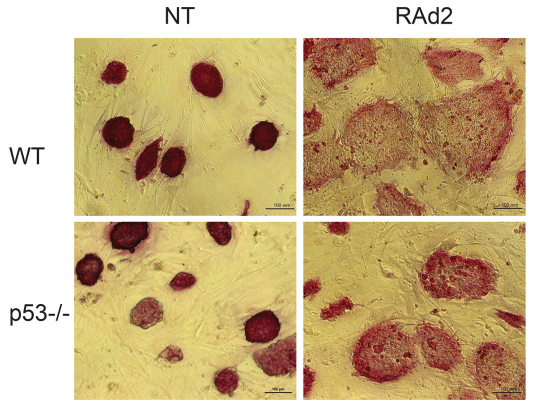

C

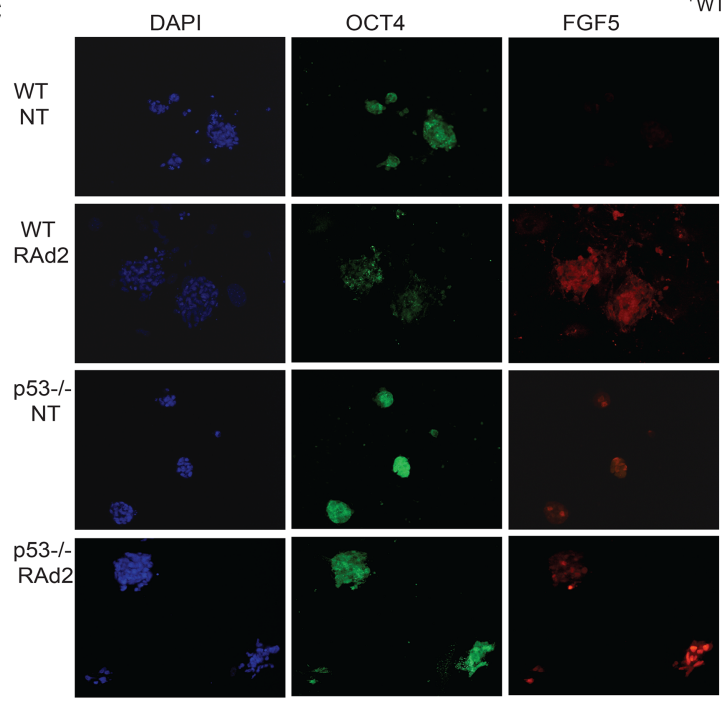

B

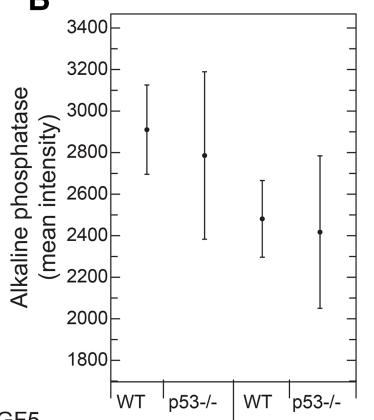

RA
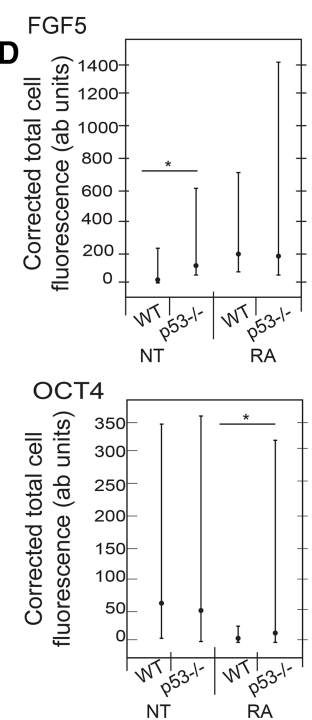

Figure 5. p53 regulates ESC clonal phenotypic heterogeneity. (A) AP activity staining of wild-type (WT) and p53 $3^{-/-}$mESCs cultured in $2 \mathrm{i}+$ LIF or treated for $2 \mathrm{~d}$ with $1 \mathrm{mM}$ RA. ESCs from both genotypes were seeded in 96well tissue culture plates (200 cells per well, a total of 18 wells per each clone). AP activity was measured as described in the Materials and Methods. (B) ESCs from both genotypes were seeded in 96-well tissue culture plates (200 cells per well, a total of 18 wells per each clone). AP activity was measured as in $A$. The quantification of the mean AP staining intensity per colony and the standard deviation are shown. For each genotype, values were averaged from all corresponding wells, representing two clones from each genotype. $(C)$ Immunostaining of wild-type and $\mathrm{p} 53^{-/-}$mESCs cultured on gelatin-coated coverslips either in $2 \mathrm{i}+\mathrm{LIF}$ (nontreated [NT]) or following $2 \mathrm{~d}$ of RA treatment. Cells were stained for OCT4 and FGF5; DAPI was used to visualize nuclei. $(D)$ Corrected FGF5|OCT4 fluorescence intensity, calculated by subtracting the background from the FGF5\OCT4 signal and dividing by colony area. The graph represents averaged values from $\sim 40$ colonies for two wild-type and two $\mathrm{p} 53^{-/-}$mESC clones. depletion increased overall $5 \mathrm{mC}$ levels also in hESCs. Moreover, the extent of variability among individual cells also significantly increased (Fig. 6B). Of note, while expression of DNMTs in hESCs was not significantly altered by p53 knockdown, we observed a prominent decrease in TET2 mRNA and a milder decrease in TET1 mRNA (Fig. 6C). Thus, in both hESCs and mESCs, depletion of p53 augments the extent of DNA methylation and its heterogeneity within the cell population, likely as a consequence of an imbalance in the methylation-demethylation machinery.

\section{Discussion}

In the present study, we report that p53-deficient mESCs fail to maintain proper DNA hypomethylation in naïve ground-state conditions, and a similar phenomenon is observed also in hESCs. This appears to be largely due to the fact that p53 is responsible for keeping Dnmt3a and Dnmt3b levels relatively low in naïve mESCs while supporting Tet1 and Tet2 expression. Consequently, p53 loss results in aberrantly augmented expression of Dnmts and compromised Tet 1 and Tet 2 expression. The imbalance in the DNA methylation machinery in $\mathrm{p}^{-/-}$ mESCs leads to not only overall elevated DNA methylation but also locally deregulated methylation setting and greater cell-to-cell heterogeneity in methylation patterns. Conversely, upon exposure to differentiation signals, p53 turns from a positive regulator of Tet genes into a negative regulator of Tet genes. Consequently, p53-/- $\mathrm{mESCs}$ fail to shut off Tet expression effectively and re-establish appropriate stable DNA methylation. These molecular defects may account for the increased phenotypic heterogeneity of $\mathrm{p} 53^{-1-}$ mESCs as well as their compromised ability to turn off pluripotency genes efficiently and turn on lineage-specific genes in response to differentiation cues.

The observations described here relate to the role of p53 in naïve ESCs. We have not determined experimentally to what extent they apply also to ESCs grown under standard conditions; however, given that the impact of p53 loss on overall DNA methylation is attenuated upon RA treatment (Supplemental Fig. S2, cf. A and D), we expect that it may also become less pronounced in regular culture conditions as compared with naïve conditions. p53 is broadly known as "guardian of the genome" (Lane 1992), a concept developed largely through analysis of somatic cells. As such, p53 contributes to the maintenance of genomic stability both under basal conditions and in response to various genotoxic stresses. Likewise, in ESCs, p53 not only ensures genomic integrity after genotoxic insults but also controls their proliferation and differentiation (Krizhanovsky and Lowe 2009). We now show 
A
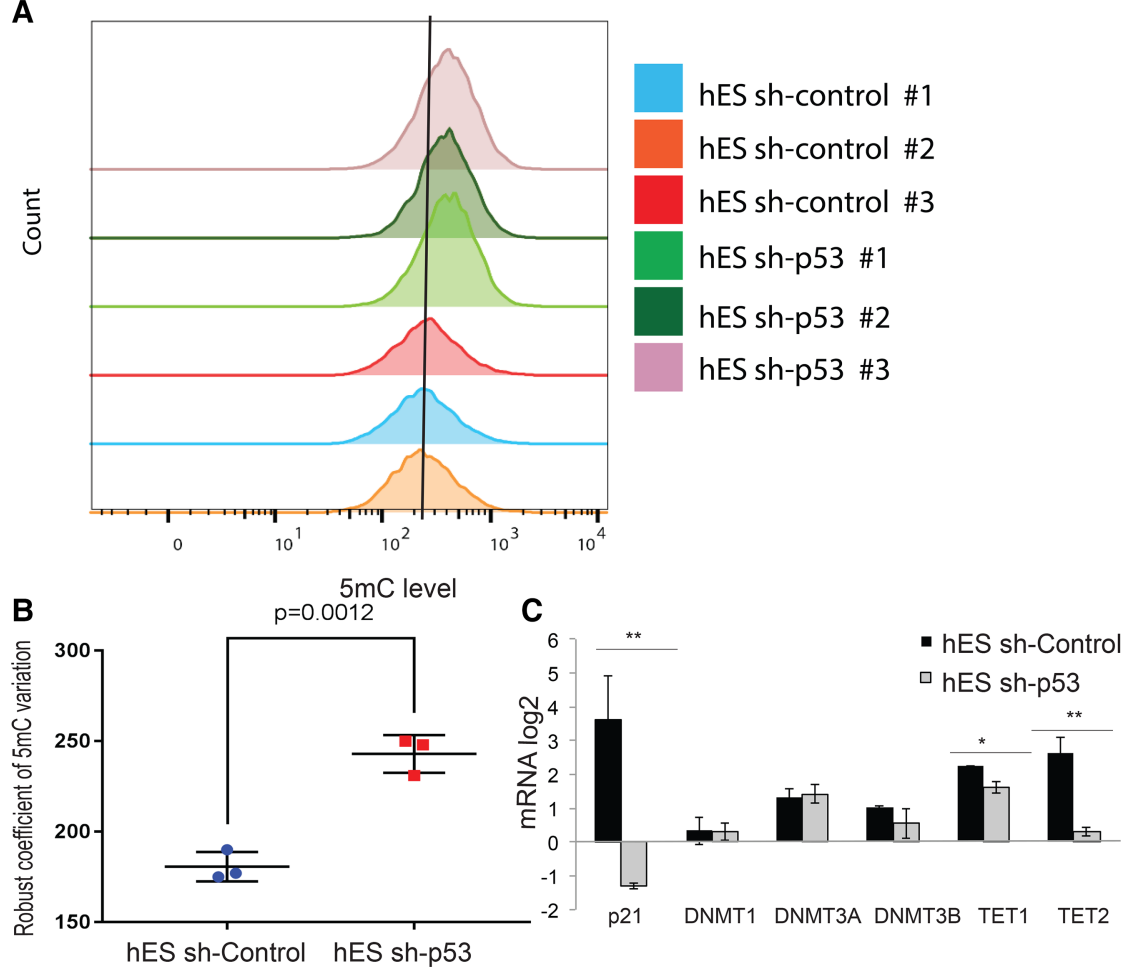

Figure 6. Depletion of p53 increases DNA methylation level and heterogeneity in hESCs. (A) Histogram overlays of $5 \mathrm{mC}$ levels in three replicates of hESCs stably expressing either control shRNA (sh-control) or p53 shRNA (sh-p53). (B) Relative distribution of $5 \mathrm{mC}$ values in sh-Control and shp53 hESCs, as represented by robust coefficient of variation, based on the data in $A$. Robust coefficient of variation was calculated using the FloJo software. (C) RNA prepared from sh-Control and sh-p53 hESCs was subjected to qRT-PCR analysis of the indicated genes. that, by controlling the DNA methylation/demethylation balance, p53 also plays an important role in ESCs as "guardian of the epigenome." The disordered methylation pattern in $\mathrm{p} 53^{-/-}$mESCs is probably largely due to a global gain of methylation owing to the distorted Dnmt/Tet balance. However, the deregulated expression of particular p53-activated and p53-repressed genes in those cells may also contribute to the observed changes in DNA methylation patterning.

Based on its better p53 binding (Fig. 1D) and performance in luciferase reporter assays (Supplemental Fig. $\mathrm{S} 1 \mathrm{H})$, Tet1 appears to be a stronger p53 target in naïve mESCs than Tet2, which is in line with published ChIPseq data (Li et al. 2012). In regard to the mechanism of Dnmt3 $a$ and Dnmt3b repression, it has been concluded recently that p53-driven transcriptional repression is not mediated by direct binding (Fischer et al. 2014), calling into question the functional significance of the relatively weak p53-binding signal obtained in Figure 1B. Indeed, the corresponding genomic regions do not contain easily recognizable p53-binding motifs, suggesting that p53 may be recruited to those regions indirectly through association with other DNA-binding proteins. Repression of DNMTs by p53 has already been reported (Jinawath et al. 2005; McCabe et al. 2005; Lin et al. 2010; Tang et al. 2012; Ma et al. 2015) and was partly ascribed to the ability of p53 to quench E2F transcriptional activity (Kimura et al. 2003; Polager and Ginsberg 2009; Tang et al. 2012). Furthermore, p53 transcriptionally induces miR-29, which targets all three DNMT transcripts (Yan et al. 2015).

Knockout of Dnmt3a and Dnmt3b in ESCs results in massive hypomethylation (Chen et al. 2003), supporting the notion that up-regulation of these enzymes by the absence of p53 may contribute to the global increase in $5 \mathrm{mC}$ in $\mathrm{p} 53^{-/-}$mESCs. We now show that the involvement of p53 in the regulation of ESC DNA methylation extends beyond DNMTs, encompassing also direct transcriptional regulation of the demethylation machinery.

The dynamic equilibrium between DNA methylation and demethylation is important for maintaining the clonal homogeneity of ESCs (Shipony et al. 2014). In contrast, somatic cells that have much lower Tet levels and hence cannot rapidly demethylate their DNA tend to acquire "epimutations" and maintain them stably, leading to a gradual increase in interclonal heterogeneity (Shipony et al. 2014). Our findings suggest that, by maintaining high Tet expression, p53 helps to sustain a dynamic DNA methylation/demethylation balance in both mESCs and hESCs. Loss of p53 tilts the equilibrium and markedly skews the genomic deposition of $5 \mathrm{hmC}$, resulting in increased heterogeneity as well as a reduced ability to maintain stable expression of pluripotency genes.

Notably, ablation of p53 greatly facilitates the reprogramming of differentiated somatic cells into ESC-like iPSCs, indicating that p53 serves as an effective barrier against loss of differentiated features (Krizhanovsky and Lowe 2009). The reprogramming process entails erasure of differentiation-associated DNA methylation in order to enable re-expression of pluripotency genes. Interestingly, we found that, in cells exposed to differentiation signals, p53 actually seems to contribute to the shutoff of Tet 1 and Tet2, suggesting that the change in signaling context might convert p53 from an activator to a repressor of those genes. The underlying mechanism remains 
unknown; one possibility is that while p53 binds its cognate target sequences in Tet 1 and Tet2 regardless of differentiation state, it recruits different chromatin modifiers in each condition, leading to either active or repressive chromatin (Espinosa and Emerson 2001). The repressive effect is maintained also in differentiated cells, as p53 ${ }^{-/-}$mouse embryonic fibroblasts (MEFs) express more Tet1 mRNA than their wild-type counterparts (data not shown). It is thus plausible that the enhancing effect of p53 depletion on iPSC reprogramming may be partly due to the increased Tet activity in p53-depleted differentiated cells, facilitating reversal of their otherwise stable DNA methylation. As shown here, down-regulation of p53 augments the extent and heterogeneity of DNA methylation also in hESCs, perhaps by restricting TET expression. The failure to observe an effect on DNMT expression might be due to the fact that the hESCs were not maintained in truly naïve conditions, although we cannot rule out species-specific differences.

Our findings indicate that p53-deficient mESCs are highly heterogeneous not only with respect to their methylation pattern but also phenotypically. Thus, while some of the cells are clearly aberrant, others still retain a perfectly normal methylation landscape and differentiation capacity. By extrapolation, one might predict that some p53-null embryos would develop perfectly normally, while others would be aberrant to varying extents: Those carrying mild methylation imbalances will be born but will exhibit developmental defects, while those with more severe methylation defects will probably be eliminated early during gestation. Indeed, in addition to the well-documented exencephaly seen in a variable proportion of p53 ${ }^{-/-}$embryos (Sah et al. 1995), it is a common observation in many laboratories that, upon prolonged breeding of $\mathrm{p} 53^{+/-}$mouse colonies, $\mathrm{p} 53^{-/-}$pups tend to be born at a lower than Mendelian ratio; the extent of this effect may vary with genetic background of the mice. Interestingly, in some cancers, following treatment with drugs that interfere with DNA methylation, p53 functions to eliminate cells that have undergone major epigenetic alterations (Levine 2017). p53 may therefore drive the elimination of cells that have undergone extensive epigenetic alterations. Thus, p53 dysfunction may promote not only genomic instability but also epigenomic instability.

In sum, we show that p53 is important for balancing DNA methylation dynamics in ESCs, keeping the bulk of the DNA properly hypomethylated. In light of the growing evidence that epigenetic aberrations play critical roles in driving cancer, it is plausible that the ability of p53 to maintain DNA methylation balance is an important contributor to its tumor suppressor capacity and that loss of p53 may contribute to cancer initiation by increasing cellular heterogeneity and epigenetic promiscuity.

\section{Materials and methods}

Isolation and culture of mESCs

129s-Trp53tm2Tyj/J p53 ${ }^{+/-}$(Jackson Laboratory) heterozygous p53 ${ }^{+-}$male and female mice were time mated. E2.5 morulas were isolated from the uteri of female mice and allowed to attach to irradiated MEF feeder layers in 2i medium. Subsequently, $2 \mathrm{i}$ medium was changed daily. Altogether, we obtained two male and one female wild-type mESC lines and one male and two female $\mathrm{p} 53^{-/-} \mathrm{mESC}$ lines. For differentiation experiments, feeders were depleted by $30-45 \mathrm{~min}$ of incubation on $0.1 \%$ gelatin followed by gentle aspiration of purified mESCs. For RA-induced differentiation, feeder-depleted cells were seeded on gelatin and transferred to differentiation medium containing $1 \mu \mathrm{M}$ RA. RA was replenished daily for $4 \mathrm{~d}$. All mouse procedures were performed under the approval of the Institutional Animal Care and Use Committee (IACUC; no. 01280213-5).

\section{Culture media}

$2 \mathrm{i}$ medium consisted of DMEM containing $7.5 \%$ knockout serum replacement, $4 \mathrm{mM}$ glutamax, $1 \times$ nonessential amino acids, $1 \mathrm{mM}$ pyruvate, antibiotics, $0.1 \mathrm{mM} 2$ - $\beta$-mercaptoethanol (2-B-ME), $1000 \mathrm{U} / \mathrm{mL} \mathrm{LIF,} 5 \mathrm{mg} / \mathrm{mL}$ insulin (Sigma), $1 \mu \mathrm{M}$ PD0325901 (Stemgent), and $3 \mu$ M CHIR99021 (Stemgent).

Differentiation medium consisted of DMEM containing $10 \%$ FBS, $2 \mathrm{mM}$ glutamine, $1 \times$ nonessential amino acids, antibiotics, 0.1 mM 2-B-ME. For hESCs, H9 (Wicell, WA09) were cultured under feeder-free conditions in mTESR1 medium (Stem Cell Technologies) on hESC-qualified Matrigel (Corning).

\section{Genome editing by CRISPR/Cas9}

Deletion of p53 by CRISPR/Cas9 was done as described (Gundry et al. 2016). Single-guide RNA (sgRNA) was in vitro transcribed with the primers listed below using T7 polymerase IVT (New England Biolabs), purified, and mixed with $1 \mu \mathrm{g}$ of CAS9 (IDT) for 10 min. mESCs were prepared and electroporated according to the Neon Transfection System guidelines (ThermoFisher Scientific).

\section{Isolation of total RNA and real-time $q P C R$}

Total RNA was isolated using the miRNeasy mini kit (Qiagen). A $1-\mu g$ aliquot of the total RNA was reverse-transcribed using Moloney murine leukemia virus reverse transcriptase enzyme (Promega) and random hexamer primers (Amersham). Real-time qPCR was performed using SYBR Green master mix (Applied Biosystems) on a Step One instrument (Applied Biosystems). Primer sequences are detailed below. All values were normalized to $\beta$-actin in the same sample and represent the average and standard error of three independent clones of wild-type and four $\mathrm{p} 53^{-/-}$ clones unless otherwise stated.

\section{Preparation of RNA-seq libraries}

RNA from C30 and C35 wild-type clones and from all $\mathrm{p} 53^{-/-}$clones was isolated and subjected to high-throughput RNA-seq. Total RNA was processed using the TruSeq RNA sample preparation kit version 2 protocol(Illumina). Libraries were evaluated by Qubit and Bioanalyzer. Sequencing libraries were constructed with barcodes to allow multiplexing of 12 samples on one lane. $>50$ million single-end 50-base-pair (bp) reads were sequenced per sample on an Illumina HiSeq 2000 instrument. Fragments were mapped to the genome $(\mathrm{mm} 9)$ using TopHat version 2.0.5 (Trapnell et al. 2009). Differential expression between wild-type and $\mathrm{p} 53^{-/-}$ clones (fold $\geq 2)$ was analyzed by CuffDiff $(q$-value $\leq 0.01)$ (Trapnell et al. 2009).

\section{Estimation of expression methylation correlation}

For differentially expressed genes as described above, their promoter was analyzed only for regions with a minimal total 
coverage of 10. Promoter methylation levels were calculated by summing the methylated calls of all single CpGs in the promoter and dividing by the sum of their coverage.

\section{ChIP}

Feeders were depleted by 40 min of incubation on $0.1 \%$ gelatin followed by gentle aspiration of purified mESCs. Cells $\left(1 \times 10^{7}\right)$ were then fixed in $1.1 \%$ formaldehyde for $12 \mathrm{~min}$ at room temperature followed by quenching with $0.125 \mathrm{M}$ glycine. Nuclei were isolated, and DNA was sheared by sonication to fragments of $\sim 300 \mathrm{bp}$. Chromatin was precipitated using the NCL p53-CM5 anti-p53 antibody (Biosystems) or anti-Flag antibody (Sigma). After reversal of cross-links, precipitated DNA was subjected to qPCR analysis using gene-specific primer pairs (see below).

\section{Protein lysates and Western blot analysis}

Cell pellets were lysed using NP-40 lysis buffer ( $150 \mathrm{mM} \mathrm{NaCl}, 50$ $\mathrm{mM}$ Tris at $\mathrm{pH} 8.0,1 \% \mathrm{NP}-40$ supplemented with phosphatase inhibitor cocktails 2 and 3 [Sigma] and protease inhibitor mix [Sigma]). Pellets were vigorously vortexed and incubated for 30 min at $4^{\circ} \mathrm{C}$ while rotating. Lysates were then quantified using the BCA kit (Thermo Scientific) according to the manufacturer's protocol. Protein sample buffer $3 \%$ SDS, $5 \%$-mercaptoethanol, $10 \%$ glycerol, $62 \mathrm{mM}$ Tris at $\mathrm{pH} 8.0$ ) was added, and samples were loaded on SDS-polyacrylamide gels for electrophoresis. Proteins were transferred to nitrocellulose membranes, blocked with $3 \%$ milk in TBST (0.05\% Tween-20 in TBS), and incubated with primary antibodies as follows: anti-GAPDH (Millipore), anti-p53 (Biosystems), anti-Dnmt1 (Abnova), anti-Dnmt3a (Abcam), anti Dnmt3b (Abcam), anti TET2 (Abcam), and anti TET1 (GeneTex). Membranes were washed with TBST and incubated with horseradish peroxidase (HRP)-conjugated anti-IgG antibodies. Proteins were visualized using the Enhanced Chemo-Luminescence (ECL) detection kit (Amersham).

\section{Luciferase assays}

DNA containing the Tet 1 and Tet2 upstream putative p53BSs was PCR-amplified with the primers listed below and cloned into the pGL3 promoter luciferase reporter vector (Promega). Wild-type and $\mathrm{p} 53^{-1-}$ mESCs were transfected with Xfect (Clontech) according to the manufacturer's instructions. All transfections also included $70 \mathrm{ng}$ of Renilla luciferase plasmid for internal control. After $48 \mathrm{~h}$, the medium was removed, and cells were incubated for $30 \mathrm{~min}$ with $700 \mu \mathrm{L}$ of passive lysis buffer (Promega). Fifty microliters of each lysate was added to a Luciferase mix [100 mM Tris-Ac at $\mathrm{pH} 7.8,10 \mathrm{mM}$ magnesium acetate, 1 mM EDTA, $2.2 \mathrm{mM}$ ATP, $70 \mu \mathrm{M} \mathrm{D}(-)$-luciferin (Roche)] and Renilla mix $\left(80 \mathrm{mM} \mathrm{K}_{2} \mathrm{HPO}_{4}, 20 \mathrm{mM} \mathrm{KH}_{2} \mathrm{PO}_{4}, 100 \mathrm{mM} \mathrm{NaCl}\right.$, 1 mM EDTA, $2.4 \mu$ M coelenterazine [Promega]) separately. Luminescence was read in black 96-well plates (NUNC) with the aid of an Infinite M200 plate reader (TECAN).

\section{Immunofluorescence}

ESCs were grown on coverslips coated with gelatin. After $48 \mathrm{~h}$ of growth, cells were fixed in $4 \%$ paraformaldehyde (PFA) for $30 \mathrm{~min}$ at room temperature. Cells were permeabilized with $0.1 \%$ Triton for $5 \mathrm{~min}$, and slides were blocked with $5 \%$ BSA for $20 \mathrm{~min}$. Samples were then incubated for $1 \mathrm{~h}$ with primary antibodies (OCT4 SC9081 or FGF5 FL268; Santa Cruz Biotechnology), washed, and then incubated with secondary fluorescent antibody and DAPI (5 $\mu \mathrm{g} / \mathrm{mL}$ final) for $40 \mathrm{~min}$ in the dark.

\section{Mass cytometry measurement and analysis}

Cells were harvested and processed as described previously (McCarthy et al. 2017). Cells were analyzed using a CyTOF 2 mass cytometer (Fluidigm). Samples and EQ Four-Element Calibration Beads (Fluidigm) were added to a 96-well deep-well plate for autosampler running. Buffer was added immediately prior to injection, and cells were resuspended at a concentration of $5 \times 10^{5}$ cells per milliliter and run at $45 \mu \mathrm{L} / \mathrm{min}$. Data normalization was performed based on bead passport using CyTOF software (version 6.0.020, Fluidigm). Sample gating was performed as described previously (Qiu et al. 2011) to select live single cells. Histogrambased visualization was performed with FlowJo (version X10.0). SPADE was performed by running SPADE version 3.0 in Matlab (version 9.0.0.341360, Mathworks). The antibodies used for CyTOF are listed in Supplemental Table 4; all antibodies were processed for CyTOF use as described in McCarthy et al. (2017).

\section{$R R B S$ and $O X-R R B S$}

RRBS was performed according to a previously published protocol (Boyle et al. 2012). Briefly, genomic DNA was isolated using the PureLink genomic DNA kit (Invitrogen) according to the manufacturer's instructions and subjected to enzymatic digestion by MSPI (New England Biolabs) for $16 \mathrm{~h}$. Klenow polymerase (New England Biolabs) was then added to each sample for end filling and poly-A tailing followed by TruSeq adapter ligation (Illumina). The library was then pooled and subjected to either bisulfite treatment as in the RRBS protocol or to an OX-RRBS protocol using the CEGX kit (Cambridge Epigenetix). Validation of oxidation efficiency was done with the provided DNA sequences that were also A-tailed and adapter-ligated. The sequence data from this study have been submitted to Gene Expression Omnibus under accession no. GSE60209.

\section{Estimating methylation levels}

The final RRBS and OX-RRBS libraries were sequenced using the Illumina HiSeq2500 to obtain 100-bp paired-end sequencing reads. Adapter trimming and quality filtering were performed with trim_galore software (http://www.bioinformatics.babraham .ac.uk/projects/trim_galore) using default parameters for RRBS analysis. BSMAP (Xi and Li 2009) was used for read alignment (using genome build $\mathrm{mm} 9$ ) and extraction of single-base-resolution methylation levels. Total methylation levels $(5 \mathrm{mC}+5 \mathrm{hmC})$ of single CpGs were obtained from the RRBS data. $5 \mathrm{mC}$ levels were obtained accordingly from the OX-RRBS data, and $5 \mathrm{hmC}$ levels were calculated as total $-5 \mathrm{mC}$ levels. Only CpGs that were covered in all biological replicates were used for the analysis (Booth et al. 2013).

\section{Hierarchical clustering of $C p G s$}

Hierarchical clustering of CpGs from all samples (wild types and p53 $3^{-/-}$clones) was done using $k$-means $(K=10)$. Clustering was then performed using Ward's method with Euclidean distance. In the presented heat maps, the CpGs of each cluster were ordered according to their average methylation across all samples. Only CpGs for which there existed at least two samples with a methylation difference of $\geq 30 \%$ were presented. Furthermore, we divided the CpGs into two groups, with mean methylation $\leq 50 \%$ and $\geq 50 \%$.

\section{Calculation of $C p G$ density}

Genomic CpG density was calculated for 200-bp windows. We define low density as $<3 \%$, medium density as between $3 \%$ and $5 \%$, and high density as $>5 \%$. 
Tovy et al.

\section{Calculation of pattern frequency}

To define groups of RRBS segments over a set of libraries derived from each wild-type or $\mathrm{p} 53^{-1-}$ clone, we used reads that were covered by at least 20 segments. Methylation pattern frequency was computed for unmethylated, fully methylated, and partially methylated above and below $50 \%$ as described in Shipony et al. (2014).

\section{Genomic annotation}

Genomic annotations were downloaded from the University of California at Santa Cruz database based on version mm9. Genomic elements were based on their alignment with RefSeq, and promoters were defined as $2 \mathrm{~kb}$ upstream of the TSS. A genomic feature was assigned to each tile if any portion of the tile overlapped with the assigned annotation. Thus, tiles could overlap with more than one feature; for example, the same tile could be annotated as both a promoter and a gene.

\section{Differentially methylated regions}

One-hundred-base-pair tiles and differentially methylated regions were calculated with the MethylKit package (Akalin et al. 2012) using a minimum coverage of 10 per tile, a methylation difference of $30 \%$, and a $q$-value of $\leq 0.05$. Genomic annotations were calculated using HOMER (Heinz et al. 2010).

\section{Cluster analysis}

RNA clustering was performed using the Partek Genomics suite (Partek) with Pearson dissimilarity.

\section{qPCR primers}

The following primers were used for RNA analysis: m-p21 $\mathrm{F}^{\prime}$ (GGCAGACCAGCCTGACAGAT), m-p21 R' (TGGGCACTTCAGGGTTTTCT), mActB $\mathrm{F}^{\prime}$ (GCTTCTTTGCAGCTCCTTC $\mathrm{GT}$ ), mActB $\mathrm{R}^{\prime}$ (CGTCATCCATGGCGAACTG), mTET1 $\mathrm{F}^{\prime}$ (GTGGTGTGTACGTTGATTCG), mTET1 R' (TGGCAGGAC GTGGAGTTGT), mTET2 $\mathrm{F}^{\prime}$ (CTATTGCTAAATGGGTATA TCGGAGATC), mTET2 $\mathrm{R}^{\prime}$ (ATTAGGTCGCACTCGTACCA), mDnmt1 $\mathrm{F}^{\prime}$ (CGACTGGGTGACAGTGTGTACCT), mDnmt1 R' (GGTAGCCACTTTGATGTTGAAA), mDnmt3a F' (CAGC CAAGAAACCCAGAAAGA), mDnmt3a $\mathrm{R}^{\prime}$ (CCAGCCGCT CCCTTGTG), mDnmt3b F' (GAGGGCCTCAAACCCAACA), mDnmt3b R' (CATTGGTTGTGCGTCTTCGA), mEOMES $\mathrm{F}^{\prime}$ (GGCAAAGTGTTGACAAAGGG), mEOMES R' (AAGGCT TCCGGGACAACTAC), mBMP4 $\mathrm{F}^{\prime}$ (ATCAAACTAGCATGGC TCGC), mBMP4 $\mathrm{R}^{\prime}$ (CGCTTCTGCAGGAACCAA), mTGFB2 $\mathrm{F}^{\prime}$ (AGCTGCGCTTGCAGAGATTA), mTGFB2 $\mathrm{R}^{\prime}$ (TACCAA GGTAACGCCAGGAA), mNESTIN F' (TCAGATCGCTCAGA TCCTGG), mNESTIN $\mathrm{R}^{\prime}$ (TTCTCAGCCTCCAGCAGAGT), mMDM2 $\mathrm{F}^{\prime}$ (TGTCTGATAGACTGTGACCCGA), mMDM2 $\mathrm{R}^{\prime}$ (TGAGTCTCTGGACTCGGAAGA), mESRRB F' (TAGGGGTT GAGCAGGACAAG), mESRRB R' (CTACCAGGCGAGAGTG TTCC), mGATA6 $\mathrm{F}^{\prime}$ (GAGCTGGTGCTACCAAGAGG), mG ATA6 $\mathrm{R}^{\prime}$ (TGCAAAAGCCCATCTCTTCT), mPDGFRA $\mathrm{F}^{\prime}$ (AAAGGGAGGACGTTCAAGAC), mPDGFRA R' (GTTAAA GACGGCACAGGTCA), mNANOG $\mathrm{F}^{\prime}$ (AACCAAAGGATG AAGTGCAAGCGG), mNANOG $\mathrm{R}^{\prime}$ (TCCAAGTTGGGTTGG TCCAAGTCT), mOCT4 $\mathrm{F}^{\prime}$ (CCTGGCCTGTCTGTCACTCA), and mOCT4 R' (GTGTCCCAGTCTTTATTTAAGAACAAAAT).

The following primers were used for the luciferase reporter assay: mTET1 En Kpn $\mathrm{F}^{\prime}$ (ATTACCTTAAAAAAACCTTGGT GGGTGGGA), mTET1 En Bgl R' (ATAGATCTGAATCATCTT
ACTAACTAACCCT), mTET2 En Sac F' (ATGAGCTCATTTT GGGGAGCTGCTTAGAATCAA), and mTET2 En Bgl R' (ATA GATCTGAGACAGAGAGAGGGAGACAGAG).

The following primers were used for ChIP DNA analysis: mTET1En $F^{\prime}$ (GATGATTCCATGGGTCAAATTGA), mTET1En $\mathrm{R}^{\prime}$ (TGGGTTCTGGGAATCGAACT), mTET2En $\mathrm{F}^{\prime}$ (AAGCTG AATTCCGAACAAGCA), mTET2En R' (GTGCGCACAAGCC TTGAA), mDNMT1 $\mathrm{F}^{\prime}$ (ATCTTGCAGGTTGCAGACGA), mDNMT1 R' (GTCTTCCCCACTCTCTTGC), mDNMT3A $\mathrm{F}^{\prime}$ (GGAAGTGGCAGAGCAAGAGT), mDNMT3A R' (GTAGGA GGAGCAGCAAAGCA), mDNMT3B $\mathrm{F}^{\prime}$ (TGTGGACCTGTG CTCCTAGA), and mDNMT3B R' (GCAGAGGTGGCTTCCAT CTT).

The following primers were used for sgRNA: $\mathrm{F}^{\prime}$ (taatacgactcacta taGGGAGCTCCTGACACTCGGAgttttagagctagaa) and R' (taata cgactcactataGGGAGCTCCTGACACTCGGAgttttagagctagaa).

\section{Acknowledgments}

We thank Howard Cedar, Ilana Keshet, and Yitzhak Reizel for their constructive input and advice. We also thank Ehud Shapiro and the Israeli National Center for Personalized Medicine and especially Shlomit Gilad, Sima Benjamin, and Gilgi Friedlander for their kind help. We also thank Margaret Goodell for her generous help in the revision process. This work was supported in part by a Center of Excellence grant (1779/11) from the Israel Science Foundation, the Dr. Miriam and Sheldon G. Adelson Medical Research Foundation, the Minerva Foundation with funding from the Federal German Ministry for Education and Research, the German-Israeli Foundation for Scientific Research and Development (GIF), and the Moross Integrated Cancer Center. M.O. is an incumbent of the Andre Lwoff chair in molecular biology. A. Tovy was supported by a post-doctoral fellowship from the Israel Cancer Research Fund (ICRF). A. Tovy designed and performed the experiments. A.S. performed the bioinformatics analyses. Y.A. generated the ESCs and helped with their analysis. Z.S. advised on bioinformatics and performed the analysis in Figure 3. A. Tanay guided the bioinformatics analysis. E.A. helped and advised on stem cell handling. N.F. helped with experiments. R.M., K.A., and M.B. carried out the CyTOF experiments. M.O. directed the study. A. Tovy, A.S., and M.O. wrote the manuscript.

\section{References}

Akalin A, Kormaksson M, Li S, Garrett-Bakelman FE, Figueroa ME, Melnick A, Mason CE. 2012. methylKit: a comprehensive R package for the analysis of genome-wide DNA methylation profiles. Genome Biol 13: R87.

Aylon Y, Gershoni A, Rotkopf R, Biton IE, Porat Z, Koh AP, Sun X, Lee Y, Fiel MI, Hoshida Y, et al. 2016. The LATS2 tumor suppressor inhibits SREBP and suppresses hepatic cholesterol accumulation. Genes Dev 30: 786-797.

Booth MJ, Branco MR, Ficz G, Oxley D, Krueger F, Reik W, Balasubramanian S. 2012. Quantitative sequencing of 5-methylcytosine and 5-hydroxymethylcytosine at single-base resolution. Science 336: 934-937.

Booth MJ, Ost TW, Beraldi D, Bell NM, Branco MR, Reik W, Balasubramanian S. 2013. Oxidative bisulfite sequencing of 5methylcytosine and 5-hydroxymethylcytosine. Nat Protoc 8: 1841-1851.

Boyle P, Clement K, Gu H, Smith ZD, Ziller M, Fostel JL, Holmes L, Meldrim J, Kelley F, Gnirke A, et al. 2012. Gel-free multiplexed reduced representation bisulfite sequencing for largescale DNA methylation profiling. Genome Biol 13: R92. 
Carvajal LA, Manfredi JJ. 2013. Another fork in the road-life or death decisions by the tumour suppressor p53. EMBO Rep 14: 414-421.

Chen T, Ueda Y, Dodge JE, Wang Z, Li E. 2003. Establishment and maintenance of genomic methylation patterns in mouse embryonic stem cells by Dnmt3a and Dnmt3b. Mol Cell Biol 23: 5594-5605.

Chiappinelli KB, Strissel PL, Desrichard A, Li H, Henke C, Akman B, Hein A, Rote NS, Cope LM, Snyder A, et al. 2016. Inhibiting DNA methylation causes an interferon response in cancer via dsRNA including endogenous retroviruses. Cell 164: 1073.

Donehower LA, Harvey M, Slagle BL, McArthur MJ, Montgomery CA Jr, Butel JS, Bradley A. 1992. Mice deficient for p53 are developmentally normal but susceptible to spontaneous tumours. Nature 356: 215-221.

Espinosa JM, Emerson BM. 2001. Transcriptional regulation by p53 through intrinsic DNA/chromatin binding and site-directed cofactor recruitment. Mol Cell 8: 57-69.

Ficz G, Branco MR, Seisenberger S, Santos F, Krueger F, Hore TA, Marques CJ, Andrews S, Reik W. 2011. Dynamic regulation of 5-hydroxymethylcytosine in mouse ES cells and during differentiation. Nature 473: 398-402.

Fischer M, Steiner L, Engeland K. 2014. The transcription factor p53: not a repressor, solely an activator. Cell Cycle 13: 3037-3058.

Grabole N, Tischler J, Hackett JA, Kim S, Tang F, Leitch HG, Magnusdottir E, Surani MA. 2013. Prdm14 promotes germline fate and naive pluripotency by repressing FGF signalling and DNA methylation. EMBO Rep 14: 629-637.

Gundry MC, Brunetti L, Lin A, Mayle AE, Kitano A, Wagner D, Hsu JI, Hoegenauer KA, Rooney CM, Goodell MA, et al. 2016. Highly efficient genome editing of murine and human hematopoietic progenitor cells by CRISPR/Cas9. Cell Rep 17: 1453-1461.

Hackett JA, Dietmann S, Murakami K, Down TA, Leitch HG, Surani MA. 2013. Synergistic mechanisms of DNA demethylation during transition to ground-state pluripotency. Stem Cell Reports 1: 518-531.

Heinz S, Benner C, Spann N, Bertolino E, Lin YC, Laslo P, Cheng JX, Murre C, Singh H, Glass CK. 2010. Simple combinations of lineage-determining transcription factors prime cis-regulatory elements required for macrophage and B cell identities. Mol Cell 38: 576-589.

Huang Y, Pastor WA, Shen Y, Tahiliani M, Liu DR, Rao A. 2010. The behaviour of 5-hydroxymethylcytosine in bisulfite sequencing. PLoS One 5: e8888.

Jackson-Grusby L, Beard C, Possemato R, Tudor M, Fambrough D, Csankovszki G, Dausman J, Lee P, Wilson C, Lander E, et al. 2001. Loss of genomic methylation causes p53-dependent apoptosis and epigenetic deregulation. Nat Genet 27: 31-39.

Jinawath A, Miyake S, Yanagisawa Y, Akiyama Y, Yuasa Y. 2005. Transcriptional regulation of the human DNA methyltransferase $3 \mathrm{~A}$ and $3 \mathrm{~B}$ genes by $\mathrm{Sp} 3$ and $\mathrm{Sp} 1$ zinc finger proteins. Biochem J 385: 557-564.

Kimura H, Nakamura T, Ogawa T, Tanaka S, Shiota K. 2003. Transcription of mouse DNA methyltransferase 1 (Dnmt1) is regulated by both E2F-Rb-HDAC-dependent and -independent pathways. Nucleic Acids Res 31: 3101-3113.

Krizhanovsky V, Lowe SW. 2009. Stem cells: the promises and perils of p53. Nature 460: 1085-1086.

Landau DA, Clement K, Ziller MJ, Boyle P, Fan J, Gu H, Stevenson K, Sougnez C, Wang L, Li S, et al. 2014. Locally disordered methylation forms the basis of intratumor methylome varia- tion in chronic lymphocytic leukemia. Cancer Cell 26: $813-825$.

Lane DP. 1992. Cancer. p53, guardian of the genome. Nature 358: 15-16.

Leitch HG, McEwen KR, Turp A, Encheva V, Carroll T, Grabole N, Mansfield W, Nashun B, Knezovich JG, Smith A, et al. 2013. Naive pluripotency is associated with global DNA hypomethylation. Nat Struct Mol Biol 20: 311-316.

Leonova KI, Brodsky L, Lipchick B, Pal M, Novototskaya L, Chenchik AA, Sen GC, Komarova EA, Gudkov AV. 2013. p53 cooperates with DNA methylation and a suicidal interferon response to maintain epigenetic silencing of repeats and noncoding RNAs. Proc Nat1 Acad Sci 110: E89-E98.

Levine AJ. 2017. The p53 protein plays a central role in the mechanism of action of epigentic drugs that alter the methylation of cytosine residues in DNA. Oncotarget 8: 7228-7230.

Levine AJ, Greenbaum B. 2012. The maintenance of epigenetic states by p53: the guardian of the epigenome. Oncotarget 3: 1503-1504.

Levine AJ, Oren M. 2009. The first 30 years of p53: growing ever more complex. Nat Rev Cancer 9: 749-758.

Li M, He Y, Dubois W, Wu X, Shi J, Huang J. 2012. Distinct regulatory mechanisms and functions for p53-activated and p53repressed DNA damage response genes in embryonic stem cells. Mol Cell 46: $30-42$.

Lin RK, Wu CY, Chang JW, Juan LJ, Hsu HS, Chen CY, Lu YY, Tang YA, Yang YC, Yang PC, et al. 2010. Dysregulation of p53/Sp1 control leads to DNA methyltransferase-1 overexpression in lung cancer. Cancer Res 70: 5807-5817.

Ma PJ, Zhang H, Li R, Wang YS, Zhang Y, Hua S. 2015. P53-mediated repression of the reprogramming in cloned bovine embryos through direct interaction with HDAC1 and indirect interaction with DNMT3A. Reprod Domest Anim 50: 400-409.

Martin Gonzalez J, Morgani SM, Bone RA, Bonderup K, Abelchian S, Brakebusch C, Brickman JM. 2016. Embryonic stem cell culture conditions support distinct states associated with different developmental stages and potency. Stem Cell Reports 7: 177-191.

Maye P, Becker S, Siemen H, Thorne J, Byrd N, Carpentino J, Grabel L. 2004. Hedgehog signaling is required for the differentiation of ES cells into neurectoderm. Dev Biol 265: 276-290.

McCabe MT, Davis JN, Day ML. 2005. Regulation of DNA methyltransferase 1 by the pRb/E2F1 pathway. Cancer Res 65: 3624-3632.

McCarthy R, Duncan AD, Barton MC. 2017. Sample preparation for mass cytometry analysis. J Vis Exp doi: 10.3791/54394.

Molchadsky A, Rivlin N, Brosh R, Rotter V, Sarig R. 2010. p53 is balancing development, differentiation and de-differentiation to assure cancer prevention. Carcinogenesis 31: 1501-1508.

Nichols J, Smith A. 2009. Naive and primed pluripotent states. Cell Stem Cell 4: 487-492.

Palmqvist L, Glover CH, Hsu L, Lu M, Bossen B, Piret JM, Humphries RK, Helgason CD. 2005. Correlation of murine embryonic stem cell gene expression profiles with functional measures of pluripotency. Stem Cells 23: 663-680.

Park IY, Sohn BH, Choo JH, Joe CO, Seong JK, Lee YI, Chung JH. 2005. Deregulation of DNA methyltransferases and loss of parental methylation at the insulin-like growth factor II (Igf2)/ $\mathrm{H} 19$ loci in p53 knockout mice prior to tumor development. J Cell Biochem 94: 585-596.

Pisanic TR II, Athamanolap P, Wang TH. 2017. Defining, distinguishing and detecting the contribution of heterogeneous methylation to cancer heterogeneity. Semin Cell Dev Biol 64: 5-17. 
Polager S, Ginsberg D. 2009. p53 and E2f: partners in life and death. Nat Rev Cancer 9: 738-748.

Qiu P, Simonds EF, Bendall SC, Gibbs KD Jr, Bruggner RV, Linderman MD, Sachs K, Nolan GP, Plevritis SK. 2011. Extracting a cellular hierarchy from high-dimensional cytometry data with SPADE. Nat Biotechnol 29: 886-891.

Radzisheuskaya A, Le Bin Chia G, dos Santos RL, Theunissen TW, Castro LFC, Nichols J, Silva JCR. 2013. A defined Oct4 level governs cell state transitions of pluripotency entry and differentiation into all embryonic lineages. Nat Cell Biol 15: 579-590.

Rho JY, Yu K, Han JS, Chae JI, Koo DB, Yoon HS, Moon SY, Lee KK, Han YM. 2006. Transcriptional profiling of the developmentally important signalling pathways in human embryonic stem cells. Hum Reprod 21: 405-412.

Rivlin N, Koifman G, Rotter V. 2015. p53 orchestrates between normal differentiation and cancer. Semin Cancer Biol 32: $10-17$.

Sah VP, Attardi LD, Mulligan GJ, Williams BO, Bronson RT, Jacks T. 1995. A subset of p53-deficient embryos exhibit exencephaly. Nat Genet 10: 175-180.

Schnekenburger M, Dicato M, Diederich M. 2014. Epigenetic modulators from 'The Big Blue': a treasure to fight against cancer. Cancer Lett 351: 182-197.

Shetzer Y, Solomon H, Koifman G, Molchadsky A, Horesh S, Rotter V. 2014. The paradigm of mutant p53-expressing cancer stem cells and drug resistance. Carcinogenesis 35: 1196-1208.

Shin MH, He Y, Huang J. 2013. Embryonic stem cells shed new light on the developmental roles of p53. Cell Biosci 3: 42.

Shipony Z, Mukamel Z, Cohen NM, Landan G, Chomsky E, Zeliger SR, Fried YC, Ainbinder E, Friedman N, Tanay A.
2014. Dynamic and static maintenance of epigenetic memory in pluripotent and somatic cells. Nature 513: 115-119.

Siegfried Z, Cedar H. 1997. DNA methylation: a molecular lock. Curr Biol 7: R305-R307.

Singer ZS, Yong J, Tischler J, Hackett JA, Altinok A, Surani MA, Cai L, Elowitz MB. 2014. Dynamic heterogeneity and DNA methylation in embryonic stem cells. Mol Cell 55: 319-331.

Smith ZD, Meissner A. 2013. DNA methylation: roles in mammalian development. Nat Rev Genet 14: 204-220.

Tang YA, Lin RK, Tsai YT, Hsu HS, Yang YC, Chen CY, Wang YC. 2012. MDM2 overexpression deregulates the transcriptional control of RB/E2F leading to DNA methyltransferase 3A overexpression in lung cancer. Clin Cancer Res 18: $4325-4333$.

Thiagarajan RD, Morey R, Laurent LC. 2014. The epigenome in pluripotency and differentiation. Epigenomics 6: 121-137.

Trapnell C, Pachter L, Salzberg SL. 2009. TopHat: discovering splice junctions with RNA-seq. Bioinformatics 25: $1105-1111$.

Tsankov AM, Gu H, Akopian V, Ziller MJ, Donaghey J, Amit I, Gnirke A, Meissner A. 2015. Transcription factor binding dynamics during human ES cell differentiation. Nature 518: 344-349.

Xi Y, Li W. 2009. BSMAP: whole genome bisulfite sequence MAPping program. BMC Bioinformatics 10: 232.

Yan B, Guo Q, Fu FJ, Wang Z, Yin Z, Wei YB, Yang JR. 2015. The role of miR-29b in cancer: regulation, function, and signaling. Onco Targets Ther 8: 539-548.

Yanes O, Clark J, Wong DM, Patti GJ, Sanchez-Ruiz A, Benton HP, Trauger SA, Desponts C, Ding S, Siuzdak G. 2010. Metabolic oxidation regulates embryonic stem cell differentiation. Nat Chem Biol 6: 411-417. 


\section{CORRIGENDUM}

Genes \& Development 31: 959-972 (2017)

\section{Corrigendum: p53 is essential for DNA methylation homeostasis in naïve embryonic stem cells, and its loss promotes clonal heterogeneity}

Ayala Tovy, Adam Spiro, Ryan McCarthy, Zohar Shipony, Yael Aylon, Kendra Allton, Elena Ainbinder, Noa Furth, Amos Tanay, Michelle Barton, and Moshe Oren

The authors note that, in the Materials and Methods section of the above-mentioned article, details of the antibodies used for CyTOF analysis (Supplemental Table 4) were inadvertently omitted. Supplemental Table 4, which lists these antibodies, has now been added online, and the Materials and Methods section in the article has been updated to reflect this addition.

doi: $10.1101 / \operatorname{gad} .319863 .118$ 


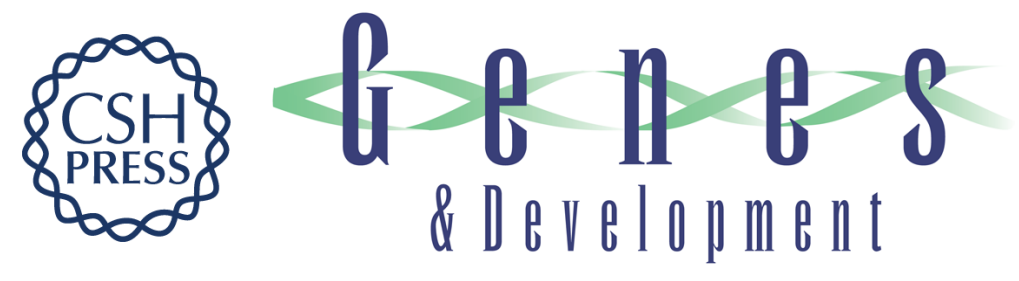

\title{
p53 is essential for DNA methylation homeostasis in naïve embryonic stem cells, and its loss promotes clonal heterogeneity
}

\author{
Ayala Tovy, Adam Spiro, Ryan McCarthy, et al.
}

Genes Dev. 2017, 31: originally published online June 12, 2017

Access the most recent version at doi:10.1101/gad.299198.117

\section{Supplemental Material \\ http://genesdev.cshlp.org/content/suppl/2017/06/12/gad.299198.117.DC1 \\ http://genesdev.cshlp.org/content/suppl/2018/10/01/gad.299198.117.DC2 \\ Related Content \\ p53: master of life, death, and the epigenome \\ Oleg Laptenko and Carol Prives \\ Genes Dev. May, 2017 31: 955-956 Corrigendum: p53 is essential for DNA \\ methylation homeostasis in naïve embryonic stem cells, and its loss promotes \\ clonal heterogeneity \\ Ayala Tovy, Adam Spiro, Ryan McCarthy, et al. \\ Genes Dev. October , 2018 32: 1358 \\ References This article cites 60 articles, 10 of which can be accessed free at: \\ http://genesdev.cshlp.org/content/31/10/959.full.html\#ref-list-1 \\ Articles cited in: \\ http://genesdev.cshlp.org/content/31/10/959.full.html\#related-urls \\ Creative This article is distributed exclusively by Cold Spring Harbor Laboratory Press for the first \\ Commons six months after the full-issue publication date (see \\ License http://genesdev.cshlp.org/site/misc/terms.xhtml). After six months, it is available under a Creative Commons License (Attribution-NonCommercial 4.0 International), as described at http://creativecommons.org/licenses/by-nc/4.0/. \\ Email Alerting Receive free email alerts when new articles cite this article - sign up in the box at the top Service right corner of the article or click here.}

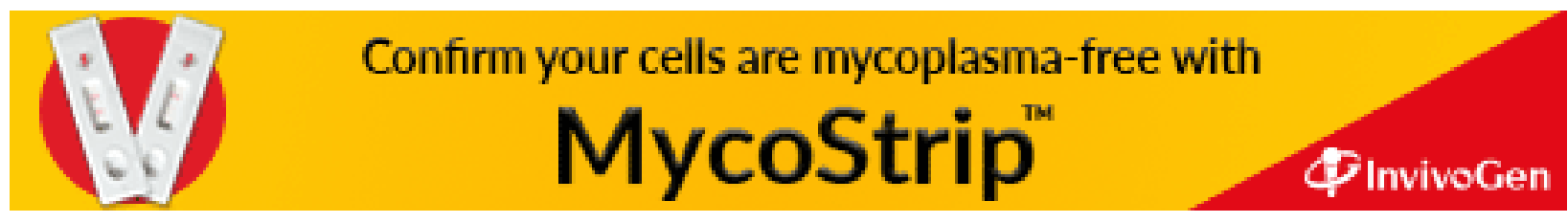

